\title{
Analysis of current practical solutions of crime mapping information systems
}

\author{
Roman Kmet* \\ Faculty of Security Engineering, University of Zilina, Slovakia \\ *Corresponding author: roman.kmet@fbi.uniza.sk

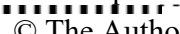 \\ 2021. \\ Published by \\ ARDA.

\begin{abstract}
Crime mapping information systems are currently a commonly used tool by public authorities, primarily for the police, security forces and services, local and regional government, as well as for the inhabitants of a certain territory. The main idea of creating these systems is to monitor and evaluate the current security situation, which is significantly affected by the active or passive activities of the police or other entities dealing with security issues. An important part is also the knowledge of the security situation on the part of the population, in which a certain state of security can evoke a feeling of security and vice versa.
\end{abstract}

Keywords: Crime; Safety; Crime mapping; Information system

\section{Introduction}

Crime is one of the aspects that most affects the sense of security of the population in a particular security environment [1]. The security situation in a particular area can be negatively affected by the occurrence and frequency of recorded crimes. The tool that enables the public as well as the professional public to get to know the criminal situation in a specific area is the information system [2], which displays selected indicators of crime in the researched region - a crime map [3]. Is an convenient tool for measuring crime. The benefits it brings to the local police and society in general are discussed in [4], where pertinence of the composed cognitive maps in the analysis of the criminal situation from a small territory perspective were made. As authors stated the instrument had a clear positive impact on the reduction and perception of crime, measurable by administrative reports and police reports, before and after the implementation of the policies associated with it. Arroyo visualised in [5] Indexed crime data utilizing self-organizing map algorithm. As he says visualization of crime data provides sufficient input to the authorities on the trends of crimes in the locality. The study clustered the indexed crime data of Misamis Occidental Philippines. Further, the study utilized SelfOrganizing Map (SOM) to visualize the data. Azmy in their research [6] utilize the method of information value modelling, a bi-variate statistical method in the layout of raster data analysis, the vulnerability of each premise are calculated based on its association with the identified burglary indicators. The results finds that 17 significant indicators out of 18 indicators are identified as index contributing to burglary susceptibility. The burglary susceptibility mapping are acquired to contribute in predicting the premise's potential risk for the sake of future crime prevention. Szyszka [7] made a qualitative analysis of solutions used in the Silesian Voivodeship, a region of Poland with a highly specific nature and density in terms of the problems discussed. The tools presented, including a "National Map of Security Threats" and "Maps of Social Problems and Resources in the Local Environment", demonstrate-apart from their obvious benefits, such as increasing public awareness of threats and enhancing cooperation between society and public institutions in combatting them-the challenges and problems that these solutions bring and may also create in the future. The research presented in [8] was to automate the processes involved in crime mapping using spatial data. The results of the baseline study were used to develop the business processes and a crime mapping model, this was implemented successfully.

The analysis of the methods used in currently used crime mapping is described.

This work is licensed under a Creative Commons Attribution License (https://creativecommons.org/licenses/by/4.0/) that allows others (c) (i) to share and adapt the material for any purpose (even commercially), in any medium with an acknowledgement of the work's authorship and initial publication in this journal. 


\section{Analysis of current practical solutions}

The crime map is currently a commonly used tool by public authorities, primarily intended for the population, but also security forces and services, to increase the sense of security of the population [9]. Within the selected region, certain crime indicators are presented, which are filtered by the users of this map based on selected criteria. In this case, we can talk about the functionalities, depending on the crime indicators that individual crime maps offer. Based on their comparison, it can be stated that some crime maps represent a greater added value, whether for the police, local governments or residents.

\subsection{Case of the Slovak Republic}

In 2013, the Ministry of the Interior of the Slovak Republic published a map of criminal offenses in SR (Figure 1). The map shows the number of crimes in individual police districts with a percentage of clarified crimes [10]. The information is freely available to the general public (residents), who can choose either general crime or a certain type of crime (economic, property, moral, violent) for a certain period (quarter, halfyear or year) [11].

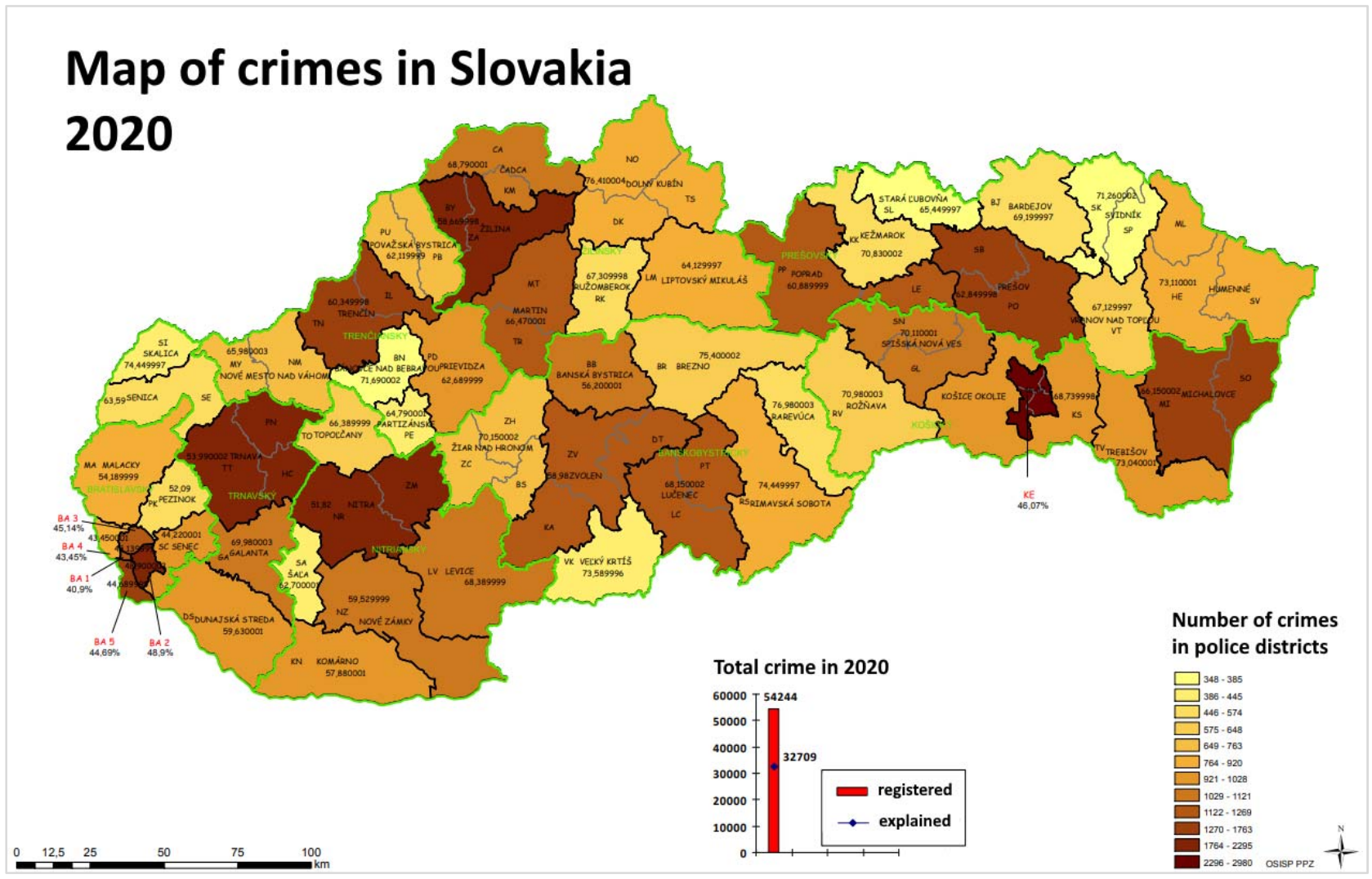

Figure 1. Map of crimes in Slovakia, the year 2020 [10]

However, this map brings with it some shortcomings that can distort the real state of crime. First, we can mention the fact that the map works with absolute and not relative data [12]. This means that the crime map shows the overall status and not the level of crime, which results in the absence of a crime rate. The map has up to 12 categories of crimes, each with a different color. Clarification rate is expressed as a percentage rounded once to two decimal places and once to six. Somewhere the character "\%" is listed and somewhere it is missing. Based on these facts, the map can have a misleading, chaotic and confusing impression [11].

\subsection{Case of the Czech Republic}

The primary reason for the creation of this application was the need to share the content of information processed by the Police of $\mathrm{CZ}$ to locate crimes and administrative offenses with the public and selfgovernment entities in CZ. The application thus combines in one place information on the occurrence of offenses registered by the Police of $\mathrm{CZ}$ so as not to violate the personal data protection of victims, their secondary victimization as well as violation of personal data protection of persons suspected of committing a crime [13]. 
The application contains basic data on administrative offenses and selected types of crimes that were reported by the Police of $\mathrm{CZ}$ in the selected period or which were registered by the Police of $\mathrm{CZ}$ through its activities (Figure 2). At the same time, only data containing location information is displayed (display of data from 2013). The application displays those types of crime in which the disclosure may be preventive and their disclosure does not hinder the tactical aspect. The type is e.g., property, violent crime, extremism, drug crime, etc. In the case of administrative offenses, the scope of the data is not limited in this way [13].

In the application, any user can view or export spatial data on the occurrence of offenses registered by the Police of $\mathrm{CZ}$ for the territory of $\mathrm{CZ}$ or individual municipalities in the territory of $\mathrm{CZ}$. This information may be further shared or used following the license for the creation of other technical means intended for crime prevention in CZ [13].

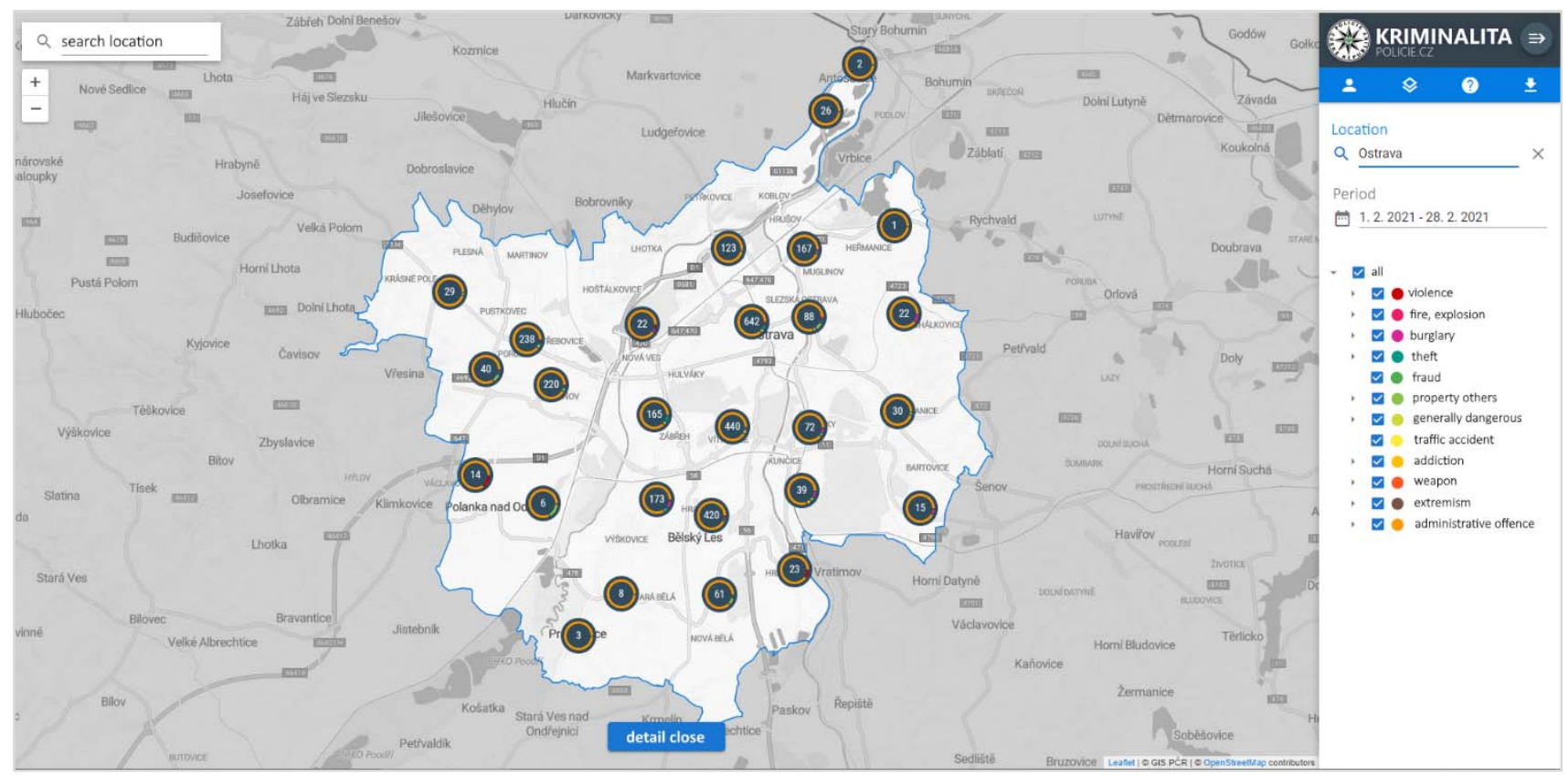

Figure 2. Display of the crime of the Ostrava police district [13]

The primary reason for the application was the need to share the content of information managed by the Police of $\mathrm{CZ}$ to locate crimes and administrative offenses with local government entities (with a focus on municipalities) in CZ. In this case, local governments, with a focus on municipalities, are considered to be an authorized user who has access to the basic functionality intended for the receipt, evaluation, analysis and sharing of published data, not only by the Police of CZ [13].

The content cards also include clear statistics within the territorial division of the municipality (Figure 3), optimization of the map for the selected location, insertion or user overview of individual offenses within the scope of the municipality and others [13].

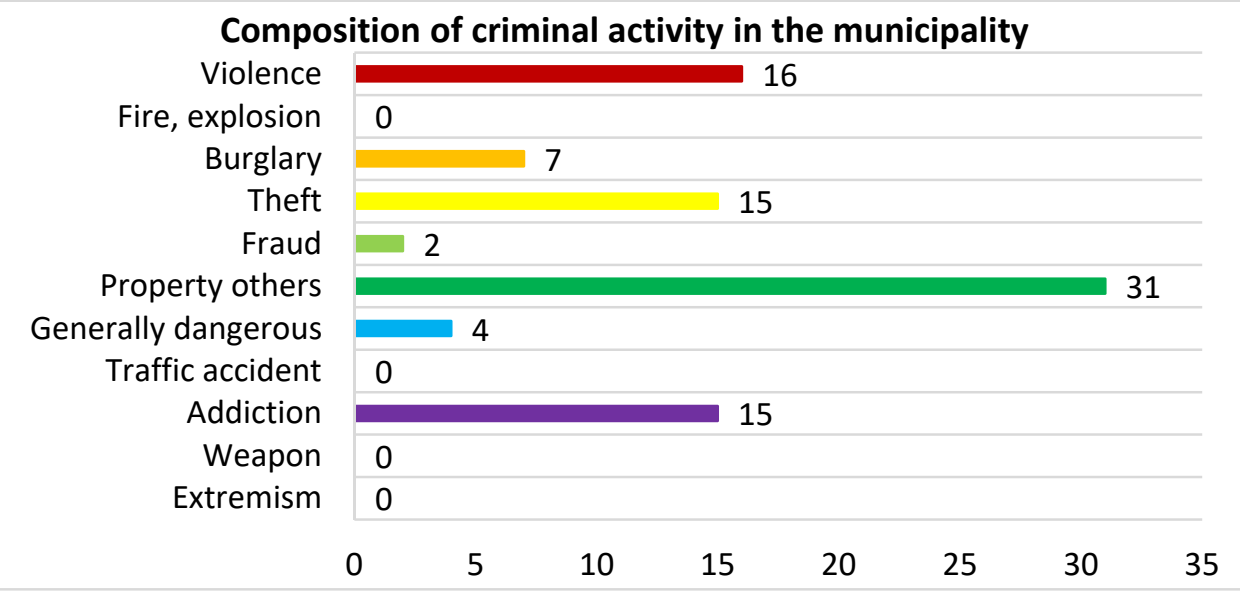

Figure 3. composition of criminal activity within a specific municipality of CZ [adopted from 13] 


\subsection{Case of United Kingdom}

The crime map website displays open data on crime and policing in England, Wales and Northern Ireland (Figure 4). The user is provided with data on crime, individual police forces or neighborhood patrols through an interactive map. Furthermore, you can easily download this data in CSV format to your PC [14]. There is also room to download data on police activities over a period and a range of other data related to police activities, including the apprehension of the perpetrator or the processing of emergency calls. All information on this website is made available under the Open Government License [14].

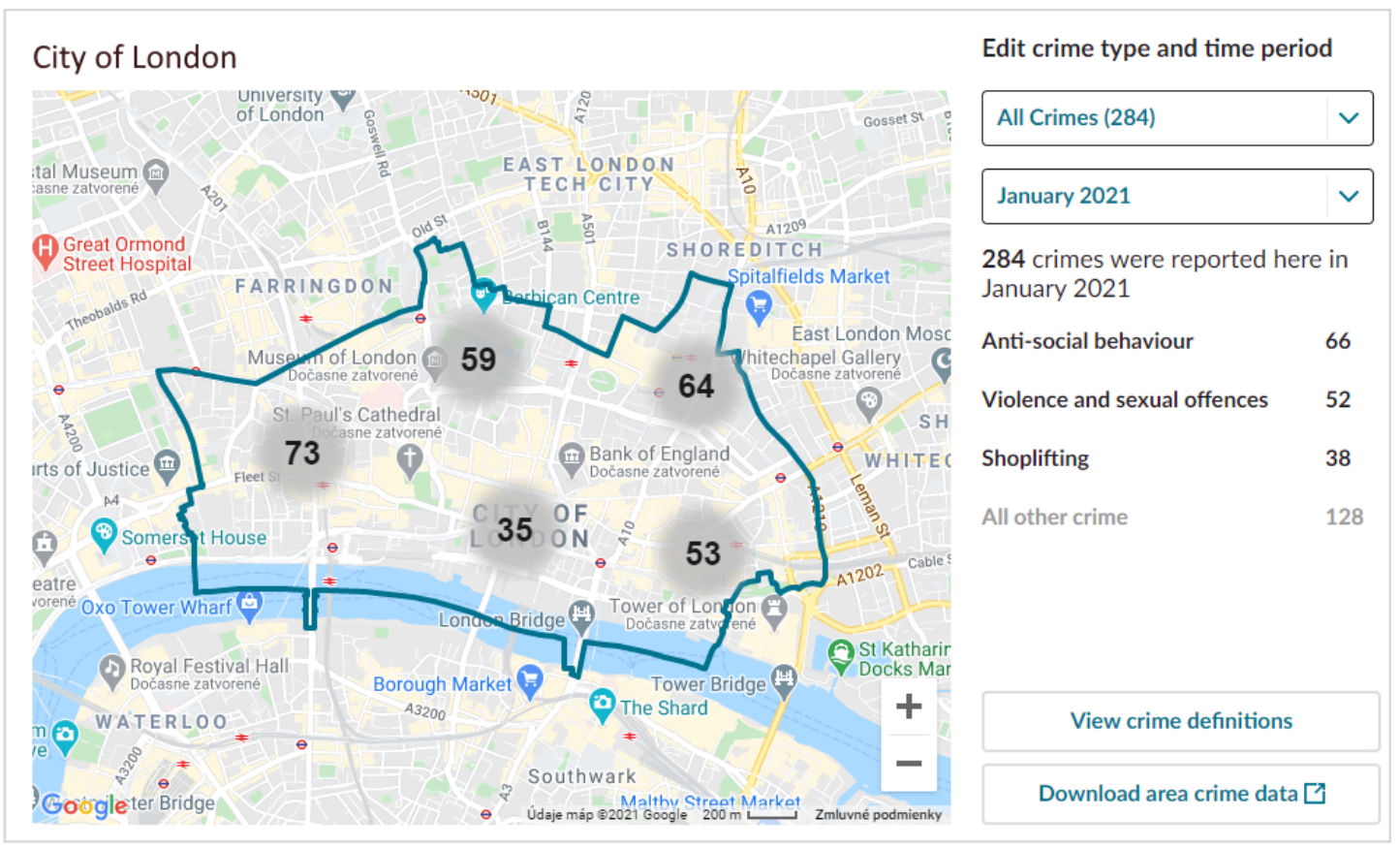

Figure 4. Crime in the city of London [14]

The data displayed by the web application provides a complete overview of crime level overview (Figure 5), type of crimes (Figure 6), the results of criminal proceedings and data on reports or searches that are statistically reported for a specific period. Published statistics are updated monthly, with the possibility of downloading data from the archive from 2013 [14].

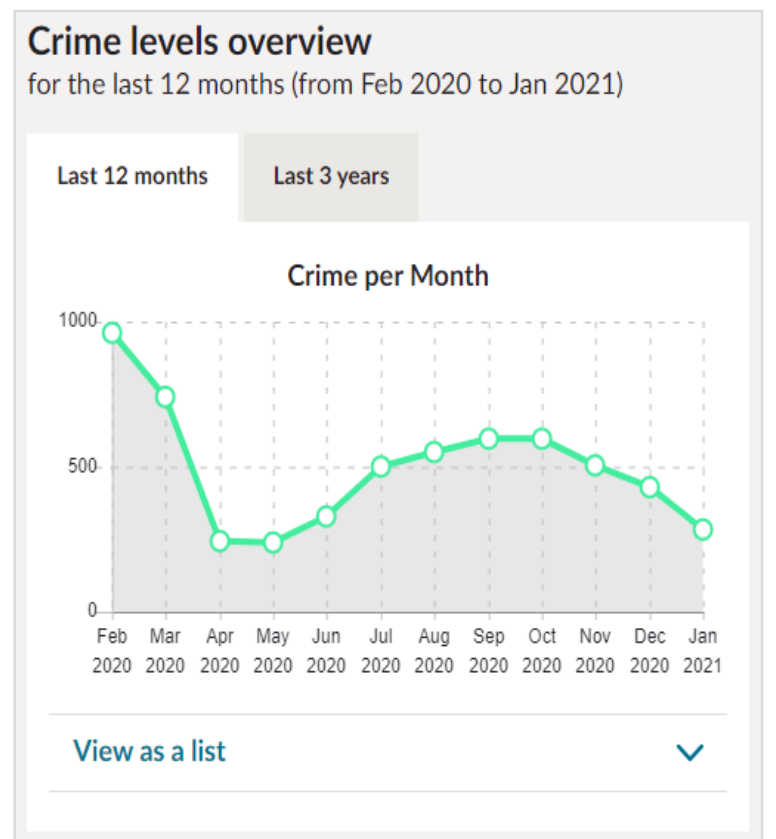

Figure 5. Display of the seasonal state of the crime of the examined locality [14]

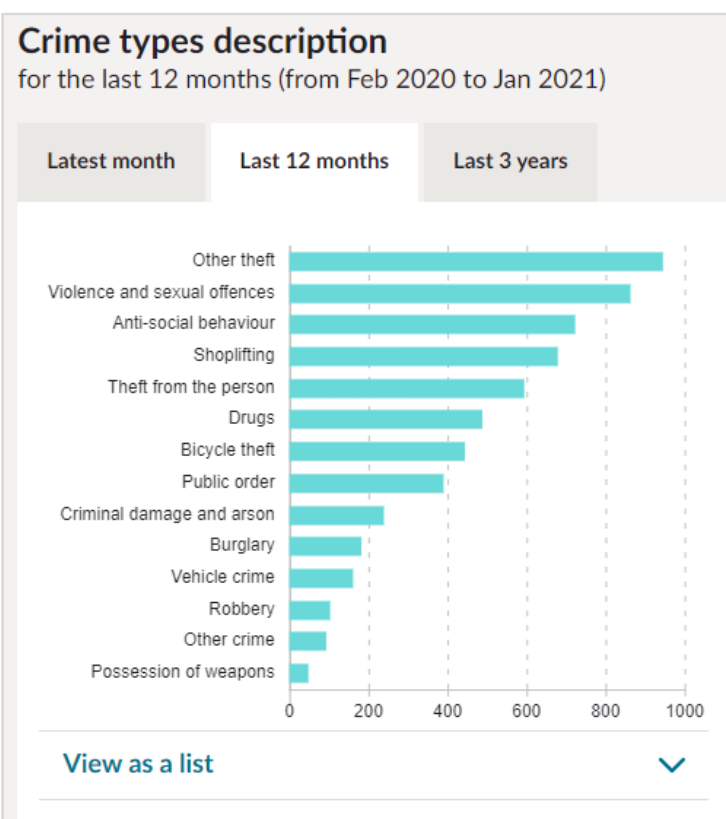

Figure 6. Display of the number of selected types of crimes of the locality [14] 


\subsection{Case of Germany}

The crime map shows brief information on the crimes, perpetrators and victims available for each region of the sixteen Länder of Germany (Figure 7). Each region is assigned a specific color, which provides an initial indication of the crime rate per 100,000 inhabitants, with the rule that the darker the color, the greater the crime burden. Within the structure of crime, selected types of crime are statistically processed, such as murder and homicide, rape and sexual assault, robbery, motor vehicle theft, drug offenses and others [15].

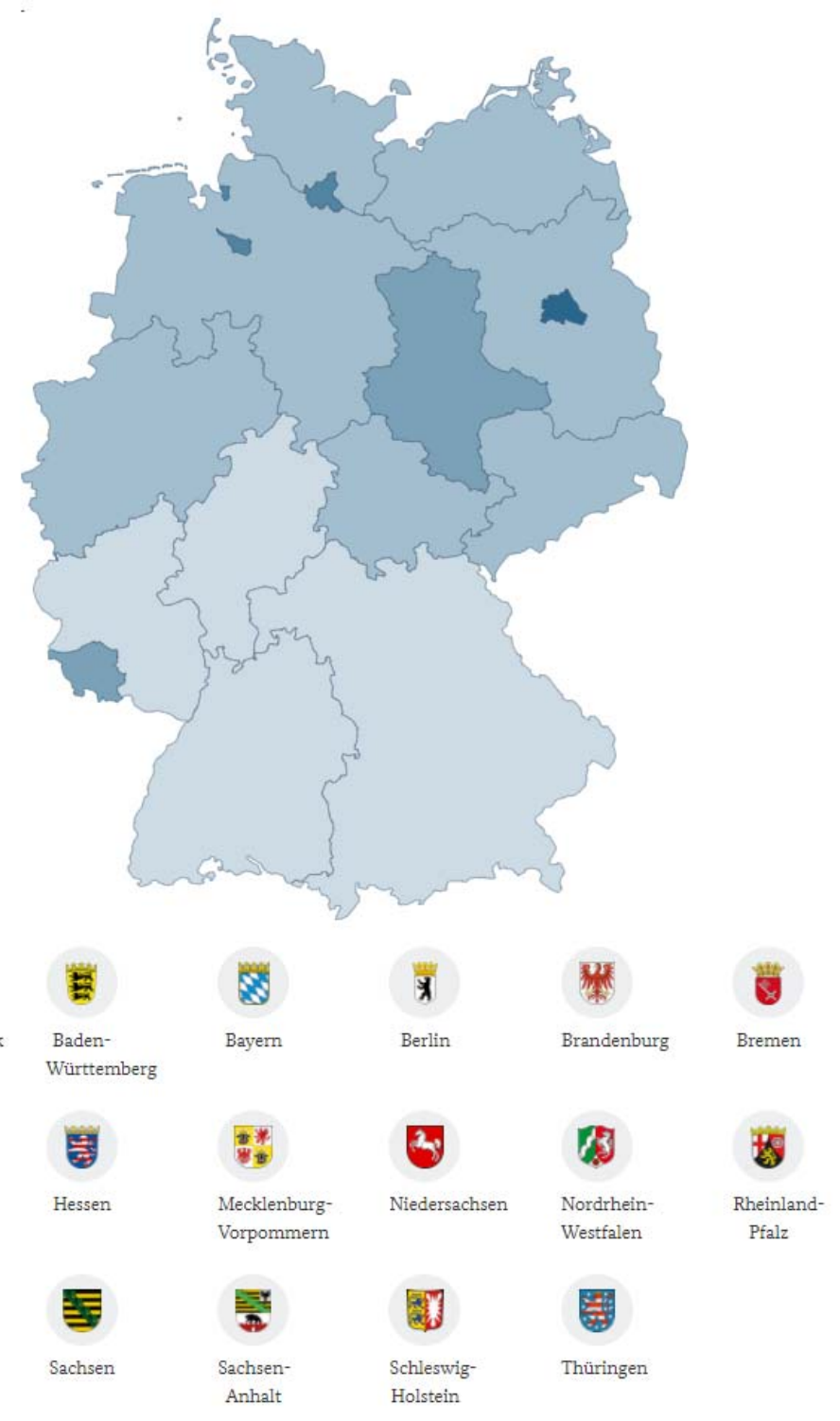

Figure 7. Interactive map of Germany - initial display of crime rate [15]

After selecting a specific area in the interactive map or the appropriate coat of arms of a specific area, the system generates a PDF document [15] that contains statistically processed data, presented in the form of graphs (Figure 8,9) and tables (Table 1).

Table 1. Development of the number of crimes and their clear-up rate in the Bavaria region [adopted from 15]

\begin{tabular}{|c|c|c|c|}
\hline \multirow{2}{*}{ Year } & \multicolumn{2}{|c|}{ Crime total } & \multirow{2}{*}{ Clear-up rate $[\%]$} \\
\hline & Reaistered & Explained & \\
\hline 2013 & 635131 & 406873 & 64,1 \\
\hline 2014 & 650868 & 419482 & 64,4 \\
\hline 2015 & 805915 & 584128 & 72,5 \\
\hline 2016 & 882473 & 581860 & 65,9 \\
\hline 2017 & 629512 & 420440 & 66,8 \\
\hline
\end{tabular}




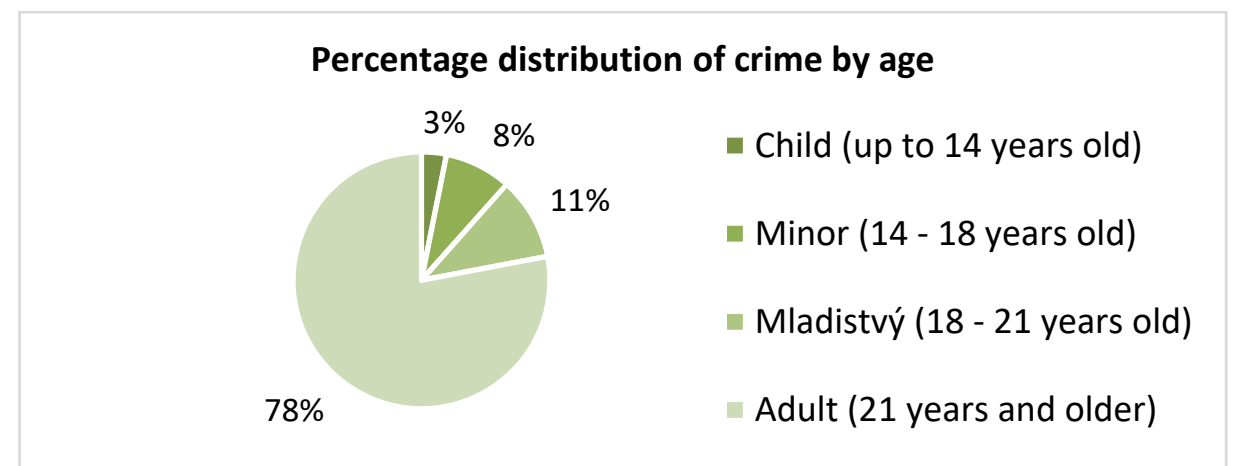

Figure 8. Graph of percentage distribution of crime in the Bavaria region by age in 2017 [adopted from 15]

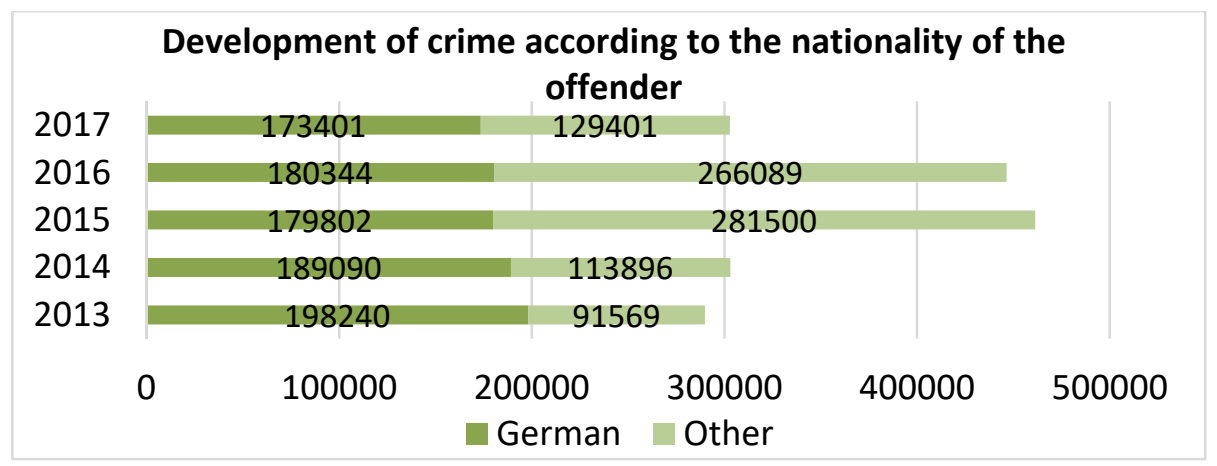

Figure 9. Graph of crime development by nationality of the offender region of Bavaria [adopted from 15]

\subsection{Case of the United States of America}

A project to map crime in US was developed to help police and law enforcement reduce the level of crime. Through better information of the population about the current state of crime in the vicinity of their residence, there is a subjective perception of crime, which can reflect the real values of crime. This fact represents the creation of greater self-confidence among the inhabitants of one defined area, who can help reduce the level of crime by their activity [16].

Crime data are obtained at regular intervals from the registration system of individual police departments, which results in the possibility of displaying the most currently available data. The extraction, processing and presentation of data are preceded by their verification, while they are generalized by blocking to ensure their protection and at the same time, they cannot be misused [16].

The interactive map offers a series of search criteria, which are used to specify the search for specific incidents of the defined space for the selected period (Figure 10) [16].

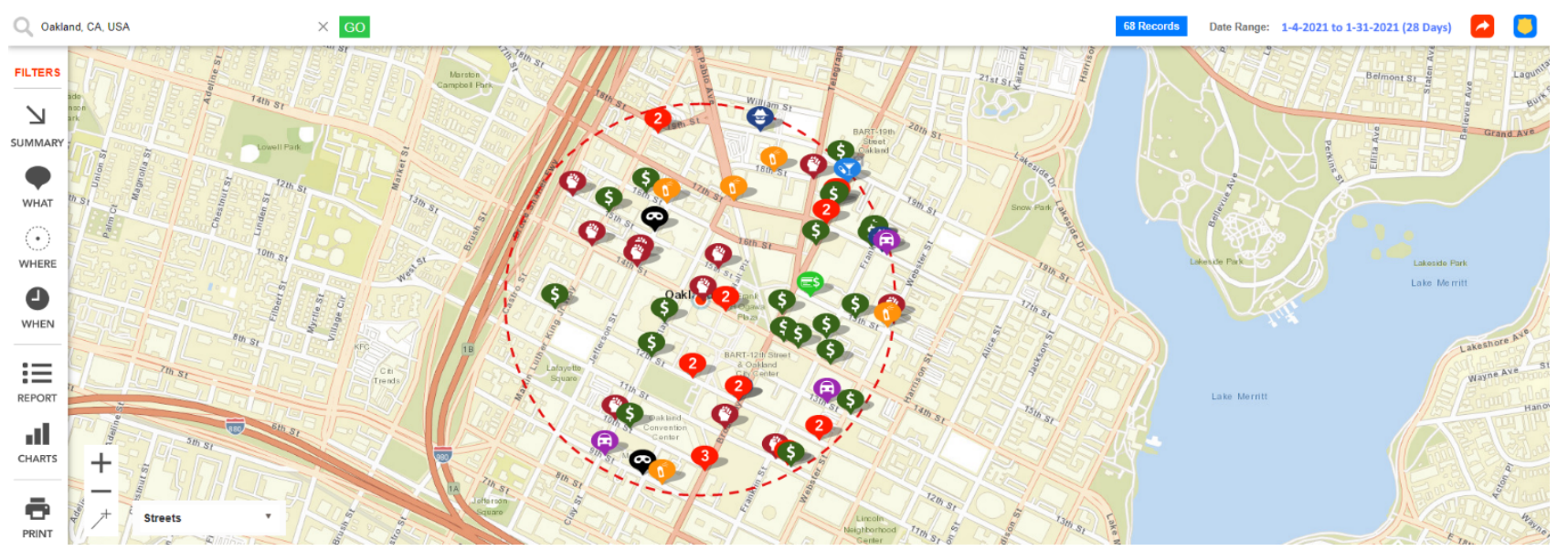

Figure 10. Showing specific incidents in Oakland, California from 01/04/2021 to 01/31/2021 [15] 
The presentation of the results of the state of the crime of the selected area and period is conditioned by the selection of criteria using a filter, the result of which is the generation of clear tables and graphs. Within the tabular output, it is possible to monitor the type and description of the incident, descriptive number, district department, date and time of the incident. Graphic outputs present the structure of crime composed of different types of incidents (Figure 11).
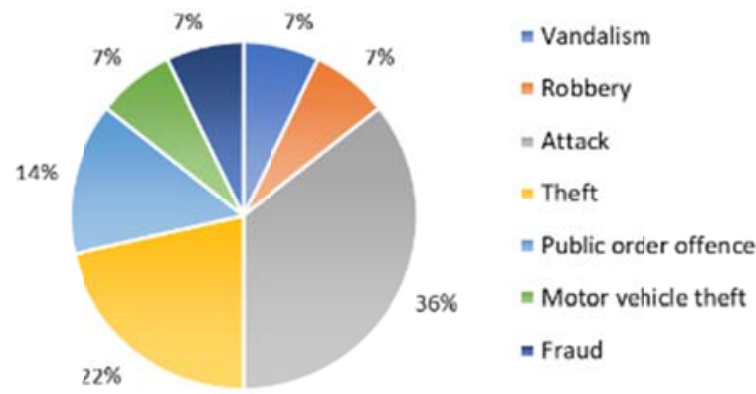

Figure 11. Daily summary of incidents from the city of Oakland, California, over time [adopted from 15]

The statistically processed data in the form of displayed incidents can be saved by the resident in their device as PDF documents with the subsequent possibility of printing.

\subsection{Case of Italy}

The criminal burden of the population in Italy is made available to the public by the Lab24 portal. It uses data provided by the Department of Public Security of the Ministry of the Interior, which reflects the crimes recorded under the authority of the state, prison, city, border police, army and coast guard. The value of the criminal burden is expressed utilizing a crime rate, which represents the number of crimes committed per population of the examined region (province) [17].

The portal thus enables the display of various statistical outputs, relative data, such as:

- display and comparison of 18 types of crimes,

- the ranking of provinces according to the overall crime rate or the crime rate of a specific type of crime,

- the first 10 provinces with the highest number of crimes,

- depiction of a specific province in the overall ranking or for a specific type of crime,

- comparison of selected provinces (Figure 12).

- display of provinces in the form of an interactive map (Figure 13) [17].

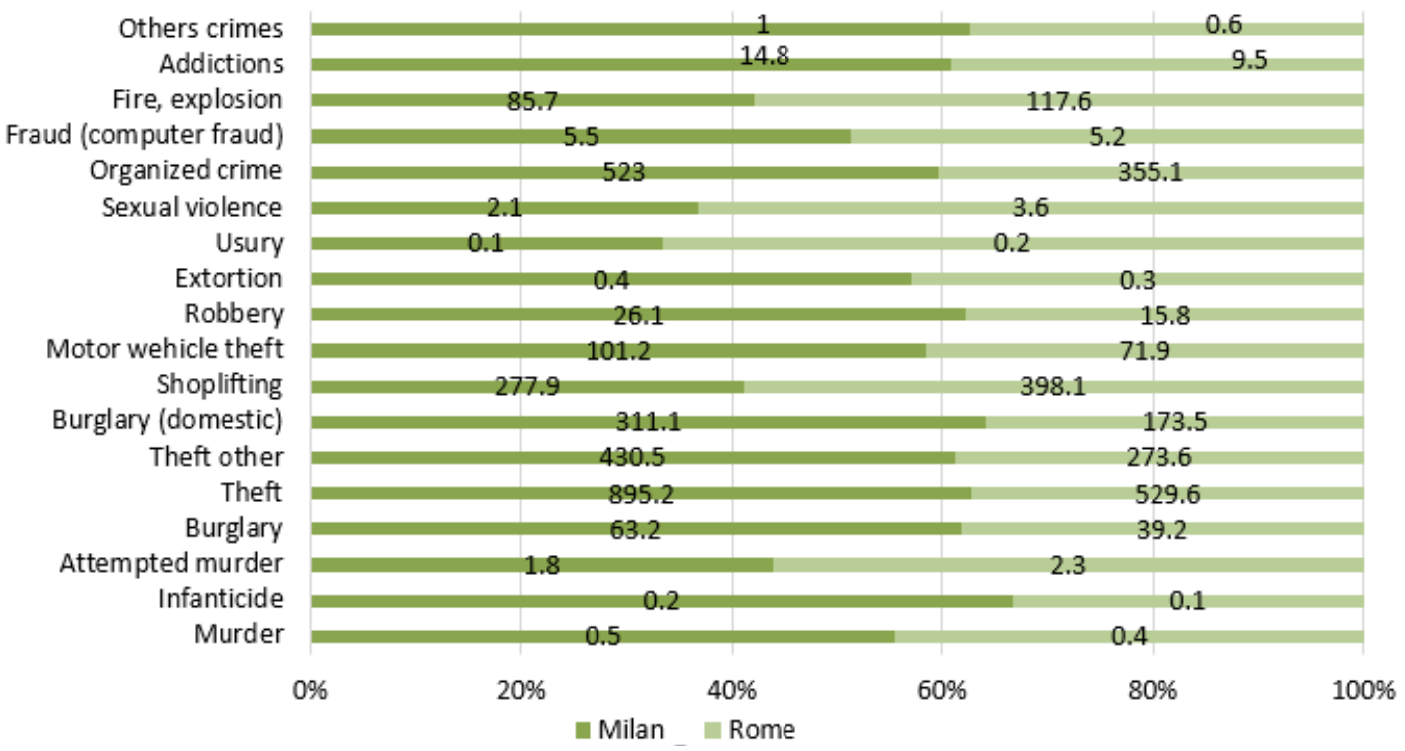

Figure 12. Graph of comparison of specific provinces in terms of individual types of crime in 2019 (value per 100 thousand inhabitants) [adopted from 17] 


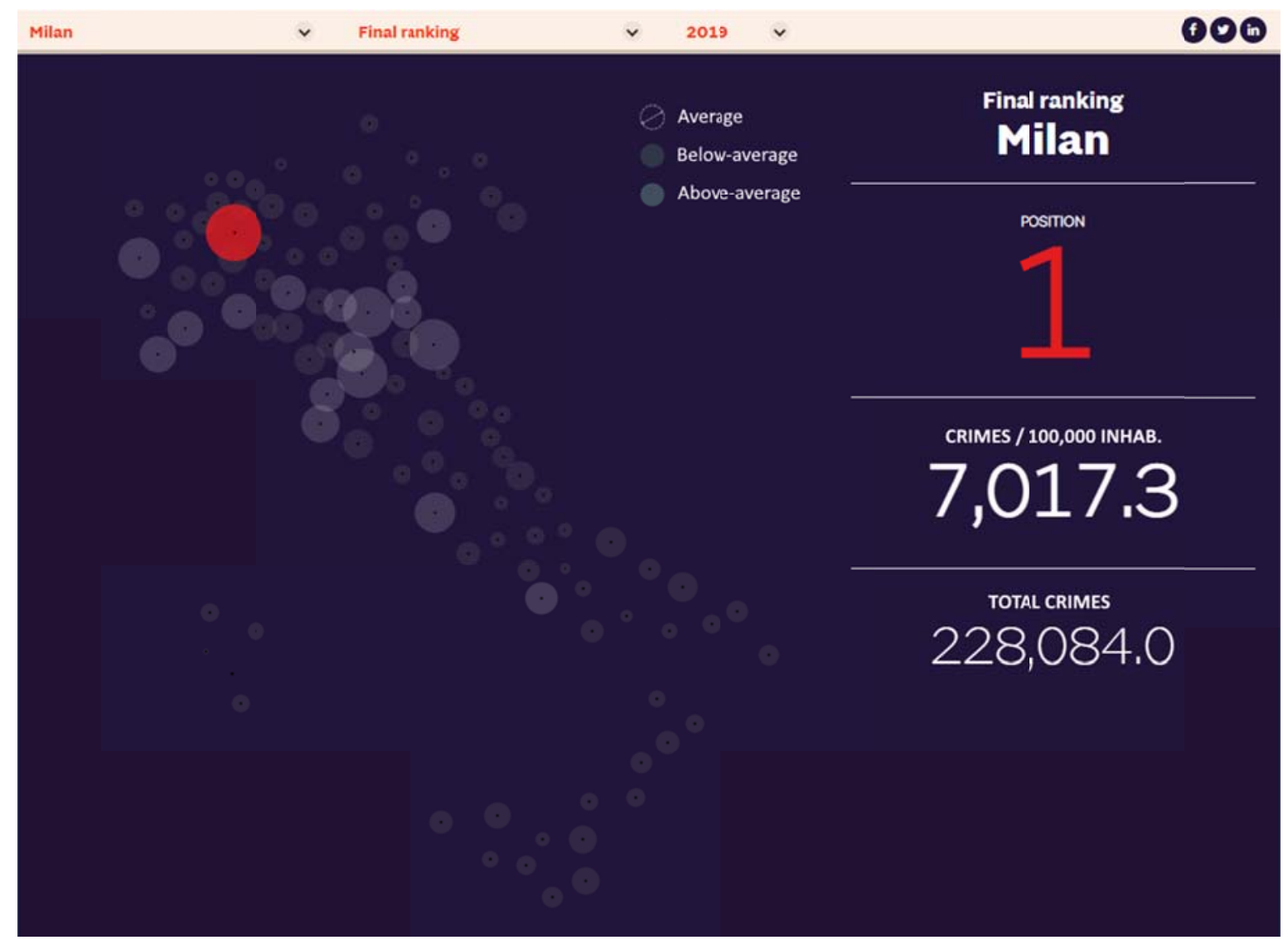

Figure 13. Interactive map showing the crime of the city of Milan in 2019 [17]

\section{Comparison of crime map functionalities of selected countries}

As crime has an interdisciplinary character, it is dealt with by many disciplines in the fields of criminology, criminalistics, juridical sciences, pedagogy, sociology, but also geography [18]. It is this aspect of security that opens the door to the creation of geographic crime mapping information systems available to several developed countries [19].

The presented crime maps differ depending on the offered functionalities, depending on the crime indicators. The degree of objectivity of the presented data, as well as its informative value, can thus be reflected in the detail of the data, the degree of updating or the interactivity of the maps.

The following Table 2 shows the functions offered for the presentation of crime in selected countries.

Table 2. Functionality comparison of individual crime maps

\begin{tabular}{|c|c|c|c|c|c|c|}
\hline Functionalities & SK & $\mathbf{C Z}$ & UK & DE & US & ITA \\
\hline Clear-up rate & $V$ & $V$ & $x$ & $V$ & $x$ & $x$ \\
\hline $\begin{array}{l}\text { Point representation } \\
\text { of crimes }\end{array}$ & $x$ & $\checkmark$ & $\checkmark$ & $x$ & $\checkmark$ & $x$ \\
\hline $\begin{array}{l}\text { Crime rate (assessed } \\
\text { area) }\end{array}$ & $x$ & $x$ & $x$ & $\checkmark$ & $X$ & $\checkmark$ \\
\hline $\begin{array}{l}\text { Crime rate (type of } \\
\text { crime) }\end{array}$ & $x$ & $x$ & $x$ & $x$ & $x$ & $\checkmark$ \\
\hline $\begin{array}{l}\text { Crime rate (trends } \\
\text { over time) }\end{array}$ & $x$ & $x$ & $x$ & $\checkmark$ & $x$ & $\checkmark$ \\
\hline Assessed area & District & $\begin{array}{l}\text { Police district } \\
\text { department }\end{array}$ & City & $\begin{array}{l}\text { Länder } \\
\text { Germany }\end{array}$ & $\begin{array}{c}\text { of Address and } \\
\text { distance }\end{array}$ & Province \\
\hline $\begin{array}{l}\text { Comparison of } \\
\text { assessed areas }\end{array}$ & $X$ & $x$ & $x$ & $x$ & $x$ & $V$ \\
\hline
\end{tabular}




\begin{tabular}{|c|c|c|c|c|c|c|}
\hline Functionalities & SK & $\mathbf{C Z}$ & UK & DE & US & ITA \\
\hline $\begin{array}{l}\text { areas } \\
\text { Graphic and tab } \\
\text { outputs }\end{array}$ & & & & & & \\
\hline Download files & $\gamma$ & $V$ & $V$ & $V$ & $y$ & X \\
\hline Data update & $\begin{array}{l}\text { Quarter / } \\
\text { Year }\end{array}$ & $\begin{array}{l}\text { Day / Month / } \\
\text { Year }\end{array}$ & $\begin{array}{l}\text { Month / Half } \\
\text { a year / Year }\end{array}$ & Year & Day / Period & $\begin{array}{c}\text { Month / } \\
\text { Year }\end{array}$ \\
\hline
\end{tabular}

As can be seen in Table 2, a part of the presentation of statistically processed crime data can be a series of crime indicators, which are displayed to the respective user through selected functionalities offered by crime maps. The informative value of these indicators, as well as their contribution to practice, in this case, depends on the final user (police, law enforcement, self-government entities or inhabitant).

\section{Result and discussion}

Because crime has an interdisciplinary character, it deals with many experts in the field of criminology, criminalistics, legal sciences, pedagogy, sociology, but also geography. It is this aspect of security that opens the door to the creation of geographic crime mapping information systems availalble to several developed countries. The presented crime maps differ depending on the offered functionalities, which reflect the level of detail of the data, the degree of updating or the interactivity of the maps.

By comparing crime maps, it is possible to point out the diversity in the presentation of the resulting values of crime. Some maps focus on displaying absolute data in the form of the number of detected crimes (crime status), others on relative data in the form of displaying a crime rate (crime assessment), which shows the number of crimes per population of the surveyed region, locality, converted to $n$ inhabitants $(n=1000,10$ 000 or 100000 ). In this case, it is a basic, globally used indicator of the crime level of a certain area [20].

If we focus on the population as the main user of the crime map, the display of the crime rate has more informative value for it than the display of the criminal status. In this case, Italy may be at the head of the above countries. The reason is a wide range of search criteria, such as clear-up rate, number of crimes, types of crimes, comparison of regions or statistical outputs in the form of various tables, graphs and figures. We attach the greatest importance to the displayed crime rate, while it is possible to monitor its time development from the past to the present.

For the needs of the Police, law enforcement or self-government entities, the crime map should support the presentation of the resulting values of crime in the form of a point display of the crimes of the selected area. The requirement of this functionality is met by the criminal map of the CZ Police. The result of this display can be the design and implementation of effective and targeted security measures.

However, account must also be taken of the fact that it is relatively questionable whether the exact location of the offenses is personal data within the meaning of the GDPR. The risk of secondary victimization increases in proportion to the decreasing population density of the study area. These are small municipalities or isolated houses, where in combination with information from the real estate cadaster, personal data can be displayed very easily. It is therefore very important to determine how and who will be responsible for the protection of personal data in the context of crime scenes [13].

Another important function of the crime map is the display of the area under consideration. As part of the comparison of maps, we can talk about the regional (area, county), local (district, city) or sub local (urban area, housing estate, street) level. Based on the facts described above, it can be assumed that the smaller the area under consideration, the more targeted and effective the security measures implemented. In this case, the collection, processing and presentation of statistics by the relevant police departments are very important.

\section{Conclusion}

Crime is a negative social phenomenon that disrupts the harmonious development of society and reduces the quality of life for individuals, social groups, and thus society as a whole [18].

The subjective perception of crime, in this case, is significantly influenced by the data that are displayed using information systems focused on crime mapping. If the final user is an inhabitant of the surveyed area, the crime map should display the level of crime through the crime rate, which is based on the number of registered crimes per number of criminally responsible inhabitants of the surveyed area, multiplied by 10,000 
or 100,000 [21]. The inhabitant can thus find out the level of crime in the space of which he is a part, which can represent for him the added value of the output of the display of crime [20].

For the needs of the police, law enforcement and self-government, the added value of the output lines in the point representation of the crimes of the assessed area. The presentation of data in this form opens the space for the application of targeted and effective security measures, which can actively contribute to reducing the level of crime, which can ultimately positively affect the perception of crime by the population.

\section{Acknowledgments}

This article was supported by the institutional grant project UNIZA Interactive Map of Offenses of the Selected Site KOR / 1041/2020

\section{References}

[1] J. Tomasek, Introduction to criminology: How to study crime, Bratislava: Grada Publishing, 2010.

[2] R. Kmet and Z. Dvorak, "Information system for evaluating the level of crime in a selected region " in Proceedings of the $2^{\text {nd }}$ year of the Scientific Conference of Doctoral Students at the Academy of the Police Force in Bratislava, 2019.

[3] L. Hofreiter and A. Byrtusova, Safety indicators. $1^{\text {st }}$ edition, Zilina: EDIS, 2016.

[4] C. D. Daniyar, P. Pihuave. et al, "The map of the victims. Pertinence of the composed cognitive maps in the analysis of the criminal situation from a small territory perspective," Politica Criminal, vol. 15, no. 30, pp. 840-870, 2021.

[5] J. C. T. Arroyo, A. J. P. Delima, M. Y. Orong, "Indexed crime data visualization utilizing self-organizing map algorithm," International Journal of Emerging Trends in Engineering Research, vol. 8, no. 9, pp. 5975-5978, 2020

[6] S. N. Azmy, M. A. Asmadi, M. Z. A. Rahman, S. Amerudin, O. Zainon, "Burglary Crime Susceptibility Assessment using Bivariate Statistics Approach of Information Value Model," IOP Conference Series: Earth and Environmental Science, vol. 540, no. 1, 012043, 2020

[7] M. Szyszka, P. Polko, "Interactive maps of social problems and security threats illustrated with an example of solutions currently used in Upper Silesia," Sustainability, vol. 12, no. 3,1229, 2020

[8] J. Phiri, C. S. Lubobya, "Crime mapping model based on cloud and spatial data: A case study of Zambia police service," International Journal of Advanced Computer Science and Applications, vol. 11, no. 1, pp. 251-265, 2020

[9] S. Matyas, "Criminal geography as a new subject in the Hungarian higher education" Criminal geographical journal. vol. 1 , no. 1, s. $45-52,2019$.

[10] Ministry of the Interior of the Slovak Republic "Map of crimes in the Slovak Republic (Mapa trestných činov v Slovenskej republike)" Electronic portal of the Ministry of the Interior of the Slovak Republic. Bratislava, 2021.

[11] R. Kmet, "Crime map in the city of Prievidza" Diploma thesis. Zilina: EDIS, 2018.

[12] M. Hornak, "Crime map in Slovakia" Denník N, Bratislava, 2015.

[13] M. Barborik, "Crime map" Project: Maps of the future II - use of spatial data for the creation and pilot verification of tools and procedures for the analysis and prediction of crime to prevent and combat it, Prague, 2020.

[14] Metropolitan Police, "Crime map for Community Policing" Electronic portal of the Police UK. London, 2021.

[15] Bundeskriminalamt, "Interactive maps" Federal Criminal Police Office. Wiesbaden, 2021.

[16] TriTech Software Systems, "Crime Mapping" San Diego, California, 2021.

[17] L. Salvioli et al., "Crime rate" Sole 24 Ore processing of data from the Public Security Department Ministry of Interior. Rome, 2021.

[18] L. Gaspierik, Prevention of crime and other anti - social activities, Kosice: Multiprint, 2010.

[19] T. Van der Heijden and E. T. Kolthoff, "Crime Analysis as a Tool for Crime Control" Proceedings of the first International Crime Analysis Conference. Haag: CIP-Gegevens Koninklijke Bibliotheek. 2010

[20] R. Kmet and Z. Dvorak, "Crime index as one of the main indicators of safety" MEST Journal. vol. 8, no. 1, s. 57-64, 2020.

[21] K. Holcr at al., Criminology. $1^{\text {st }}$ edition, Bratislava: Iura Ed, 2008. 